\title{
2. Keeping Our Distance: Non-Indigenous/Aboriginal relations in Australian society
}

\author{
Maggie Walter
}

In February 2008, then Prime Minister Kevin Rudd made a national apology to members of the Stolen Generations. For Indigenous ${ }^{1}$ and non-Indigenous Australians alike this was a significant political and social moment. The intense media and public interest in, and scrutiny of, the apology demonstrate that the relationship between the original Australians and those who have arrived since colonisation remains salient, if not central, to who Australians are what Australians and Australia is in the twenty-first century. The terrain of this relationship is key to Australia's self-concept, its identity as a nation and that of its peoples, old and new.

Yet these relations are also highly contested. The image of Australia reflected here is a two-sided visage. One face - as manifested in the apology, the elevating of Professor Mick Dodson to 2009 Australian of the Year and the groundswell of public action in the March for Reconciliation in 2000-is openly encouraging of reconciliation and acknowledging of a historical legacy of entrenched marginalisation and poverty. The other face forestalls the prospect of formal rapprochement, casting as undeserved and unearned attempts at social, economic or political equity - a position manifested by the now long-stalled reconciliation process and the commonness of publicly expressed negative sentiment towards Indigenous peoples and culture (see, for example, Andrew Bolt's 2008 blog in relation to the new Indigenous representative body). This distinctively Australian, but contradictory, picture suggests a country and a national identity ill at ease with the place of Indigeneity in its consciousness, one in which Indigeneity remains unreconciled with everyday concepts of Australian society and Australian identity. This uniquely Australian unease is reflected in the often confused and conflicting direction of public attitudes towards Indigenous people, Indigenous culture issues and Indigenous political topics. As with public conversation, supportive and reconciliatory attitudes and substantial levels of anti-Aboriginal sentiment appear to incongruously coexist as the Australian norm.

\footnotetext{
1 The term 'Aboriginal' is used in the AuSSA questions rather than the group term 'Indigenous'. This terminology is selected because the large majority of Indigenous people are Aboriginal (more than 90 per cent) and because this is the term commonly used in public discourse on Indigenous-related topics. Torres Strait Islanders are also a distinct people culturally and geographically.
} 
Explaining attitudinal and public conversation incongruence is complicated by a dearth of information on the interaction between non-Indigenous and Aboriginal Australians in everyday life. Indigenous Australians form only 2.5 per cent of the total population, but this equates to more than 500000 people and, in contrast with popular perceptions, three-quarters of these people live alongside non-Indigenous residents in regional or urban locations. Population trends also indicate that, just like the non-Indigenous population, Indigenous people are increasingly resident in larger urban areas. In 2006 nearly one-third of Indigenous Australians lived in our major cities, with many families resident in urban areas for generations (ABS 2007; Fredericks, Leitch and Barty 2008). By State, New South Wales is home to the largest proportion of the Indigenous population (28 per cent), with the largest Indigenous population resident in Sydney. Nearly the same proportion (27 per cent) resides in Queensland (27 per cent) followed by Western Australia (15 per cent) and the Northern Territory (13 per cent). As shown in Figure 2.1, in all regions except Western Australia and the Northern Territory at least 80 per cent of the Indigenous population lives in urban areas.

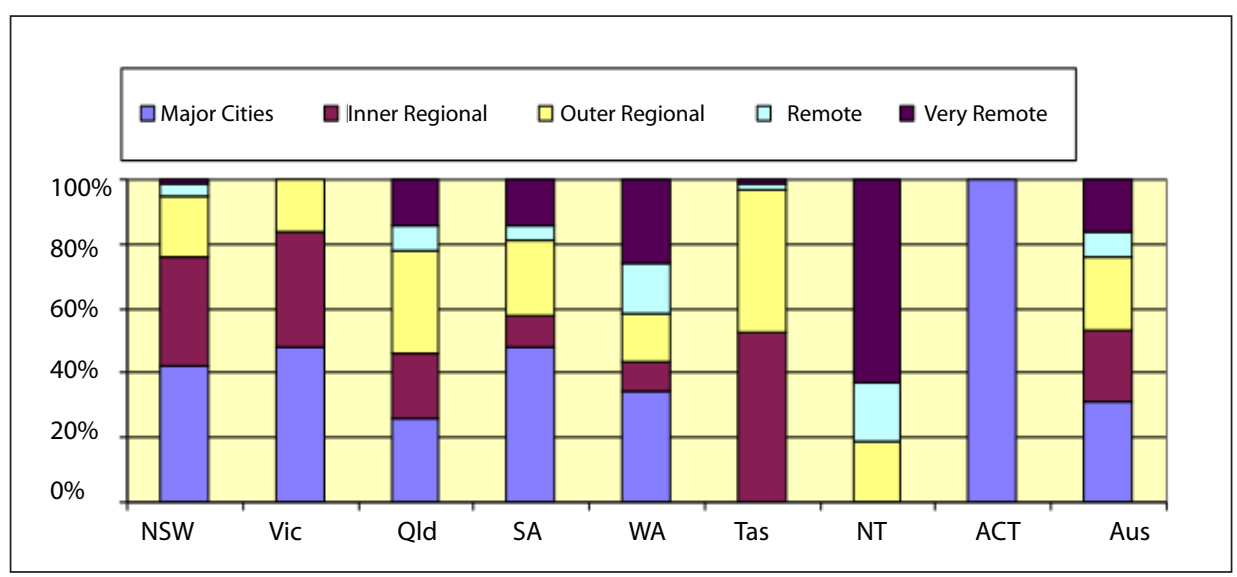

Figure 2.1 Indigenous Population Across Geographic Regions, 2006, by State/Territory

Source: ABS (2007).

This chapter's topic of an uneasy Australian identity takes two dimensions of the relations between non-Indigenous and Indigenous Australians as its empirical focus. These are: public attitudes towards Aboriginal issues, and social interaction by non-Indigenous people. The empirical analysis is guided by two questions based on these dimensions. The first queries the shape of contemporary social attitudes and whether these reflect wider socioeconomic and demographic patterns - that is: what are the patterns of non-Indigenous Australians' attitudes towards Aboriginal people, culture and issues and are these associated with demographic, social and/or economic characteristics? The 
second queries the level of individual interaction between non-Indigenous and Aboriginal Australians - that is: how socially distant from or proximate to Aboriginal people are non-Indigenous Australians? The analysis is based on data from the 2007 Australian Survey of Social Attitudes (AuSSA) in which a series of questions canvassed respondents' attitudes on a range of topical Aboriginalrelated issues (Hla to Hlf) and sought indicators on the level of respondents' social distance (H3a to $\mathrm{H} 3 \mathrm{~d}$ ) and social proximity (H2) with Aboriginal people. Bringing these two dimensions together, the overall aim of this chapter is to throw an empirical light onto the conflicting elements of the Australian landscape of race relations. In doing so it illustrates a largely unexplored, but deeply resonating, aspect of contemporary Australian life, and Australian identity, for its Indigenous and non-Indigenous peoples.

\section{Australian public attitudes}

Australian public attitudes towards Aboriginal people and issues have been variously canvassed since at least the late 1960s (see Beswick and Hills 1969; Western 1969) with the range of data collections and results summarised in a recent book by Goot and Rowse (2007). The Australian Election Studies (Bean, Gow and McAllister 2001), for instance, have asked a short series of attitudinal questions on Aboriginal topics in every collection since the 1980s. Collection of data on attitudes towards Aboriginal people, however, has remained relatively sporadic and limited and their analysis has generally been aimed at addressing wider social and public issues. For example, political science explorations of the reasons for the rise of Pauline Hanson and the One Nation in the mid-1990s found that underlying attitudes towards Aborigines were a factor (Charnock 1999; Goot and Watson 2001). The psychological underpinnings of race-related attitudes have also featured in research. For example, a small-scale study by Ray (1981) found negative attitudes towards Aboriginal people and culture associated with conservatism. More recently, WA studies (Pedersen et al. 2004; Walker 1994) find low empathetic concern correlated with negative attitudes towards Aboriginal people.

Existing research has also found that socioeconomic and demographic variables tend to be linked with attitudinal direction. For example, a recent survey study on racism (Dunn et al. 2004) found a persistence of intolerance towards Asian, Jewish and Indigenous people. Those with higher levels of intolerant attitudes were more likely to be male, older and non-tertiary educated. A cross-wave (1993-2004) analysis of Australian election studies data (Walter and Mooney 2007) on respondents' agreement with the statement 'Government help for Aborigines has gone too far' also found older, male, less educated respondents were statistically more likely to agree with the statement. This analysis, 
however, also found that public attitudes on the topic both varied and remained consistent. Respondent statement agreement levels were 46 per cent in 1993, rose to more than 50 per cent agreement in 1996 and 1998, but by 2004 had returned to their 1993 levels of just less than a majority. The period of higher agreement, 1996-98, coincides with the political influence of Pauline Hanson's One Nation party. This link suggests attitudes can be affected by dominant public discourses, but also tend to reflect an underlying population norm.

\section{Social distance and social proximity}

Even less literature directly relates to the second question: what is the level of social distance and social proximity between non-Indigenous and Aboriginal Australians? The primary research tool used to measure social distance between ethnic groups is the Bogardus social distance scale, developed in the United States in the 1920s. The scale assesses respondents' degree of warmth, indifference or hostility to levels of social relationships, which are then taken as a measure of ethnic relations and prejudice (Marshall 1998). Such studies, however, tend to analyse relations between the dominant cultural or racial group and ethnic (usually) migrant minorities, not between a non-indigenous and indigenous population - for example, an Australian representative study by McAllister and Moore (1991), examining the social distance of respondents from the majority migrant groups, finding a social distance closest to furthest continuum from European groups to Vietnamese people. Indigenous people were not included as a target group. A smaller-scale study did explore social distance from Aboriginal people, Asian people, the aged and homosexual people, finding social distance highest for homosexual people and smallest towards Aborigines (Matsuda and Harsel 1997). The low sample size and mixing of ethnic and social groups, however, reduce this study's usefulness to the inquiries in this chapter. More critically, social proximity - the level and regularity of social interaction between non-Indigenous and Aboriginal people - has not been a significant research topic, although a recent study by Reconciliation Australia (ABC 2009a) does find significant levels of distrust between the two groups. Given the spatial proximity, with the majority of non-Indigenous and Aboriginal people living alongside, the questions of social proximity and social distance have direct relevance to social attitudes. 


\section{AuSSA 2007 data and attitudes to Aboriginal people, culture and place}

To examine the first question - the shape of contemporary attitudes and whether these are patterned by socioeconomic and demographic factors - a series of six 'Aboriginal' statements was posed. Respondents were asked to indicate their level of agreement with each statement. This series was developed to reflect the essence of Aboriginal topics current in national public conversations - that is, what is being said by non-Indigenous people about Aboriginal issues in blogs and the letters pages of newspapers and on talkback radio. Two statements (Hla, Hlf) sought perceptions of the current positioning of Aboriginal people within Australian society; two statements (Hlc, Hle) canvassed attitudes to Aboriginal cultural topics, and two statements (Hlb, Hld) explored attitudes towards government policy and/or legislation that ameliorate Aboriginal disadvantage or loss. The tenor of the statements was varied from negative to positive, as was the dimensional order, to avoid response sets. In this and subsequent analyses, the four cases in the AuSSA sample who identified as having an Aboriginal or Torres Strait Islander ancestry ${ }^{2}$ are excluded.

As shown in Table 2.1, there is a patterned but varied level of agreement/disagreement across the statements. The two statements that look at equality are majority positively supported, as are both of the statements that deal with issues of culture. Nearly 60 per cent disagree (14 per cent strongly disagree and 40 per cent disagree) that Aboriginal people are now treated equally and just more than half disagree that injustices are now all in the past. Similar proportions strongly disagree (14 per cent) or disagree (43 per cent) that a traditional lifestyle defines Aboriginality and strongly agree (12 per cent) or agree (41 per cent) that cultural change should not be necessary to fit into Australian society. The two statements relating to the restorative actions of land rights and extra government assistance, however, do not receive majority support. Only 9 per cent strongly agree and 36 per cent agree ( 45 per cent in total) that Aboriginal disadvantage justifies extra government assistance. The level of disagreement with the statement that granting land rights to Aboriginal people is unfair is even lower, with only 8 per cent strongly disagreeing and 25 per cent disagreeing (33 per cent in total). These findings suggest a cognitive dissonance between egalitarian belief systems and willingness to endorse social actions to address inequality. While there is majority agreement among non-Indigenous Australians that Indigenous people remain unfairly and disadvantageously positioned, should not have to change their culture and do not have to follow a traditional lifestyle to retain their identity, the statements on land rights and extra government assistance were not equally accepted.

2 Twenty-seven respondents answered 'yes' to the question 'Do you identify as Aboriginal or Torres Strait Islander?'; however, only four respondents gave their ancestry as Australian Aboriginal on the ancestry questions and no respondents gave their ancestry as Torres Strait Islander. Cross-checking the 27 'yes' responses with ancestry responses indicates that ancestry responses are likely to be the more accurate measure of Australian Indigeneity and this has been used in this chapter. 
Table 2.1 Attitudes Towards Aboriginal Issues (per cent)

\begin{tabular}{|c|c|c|c|c|c|c|}
\hline & $\begin{array}{l}\text { How strongly do you agree or disagree with } \\
\text { the following statements? }\end{array}$ & $\begin{array}{r}\text { SA } \\
\%\end{array}$ & $\begin{array}{c}\text { A } \\
\%\end{array}$ & $\begin{array}{l}\mathbf{N} \\
\%\end{array}$ & $\begin{array}{l}\text { D } \\
\%\end{array}$ & $\begin{array}{r}\text { SD } \\
\%\end{array}$ \\
\hline a. & $\begin{array}{l}\text { Aboriginal people are now treated equally to other } \\
\text { Australians } \\
N=2624\end{array}$ & 6 & 17 & 19 & 44 & 14 \\
\hline f. & $\begin{array}{l}\text { Injustices towards Aboriginal people are now all in the past } \\
\mathrm{N}=2612\end{array}$ & 8 & 18 & 22 & 37 & 14 \\
\hline c. & $\begin{array}{l}\text { Aboriginal people should not have to change their culture } \\
\text { to fit into Australian society } \\
\mathrm{N}=2619\end{array}$ & 12 & 41 & 23 & 20 & 5 \\
\hline e. & $\begin{array}{l}\text { Aboriginal people who no longer follow traditional lifestyles } \\
\text { are not really Aboriginal } \\
N=2617\end{array}$ & 7 & 16 & 20 & 43 & 14 \\
\hline b. & $\begin{array}{l}\text { Aboriginal people's levels of disadvantage justify extra } \\
\text { government assistance } \\
N=2614\end{array}$ & 9 & 36 & 20 & 26 & 9 \\
\hline d. & $\begin{array}{l}\text { Granting land rights to Aboriginal people is unfair to other } \\
\text { Australians } \\
\mathrm{N}=2618\end{array}$ & 14 & 29 & 25 & 25 & 8 \\
\hline
\end{tabular}

Note: $\mathrm{SA}=$ strongly agree; $\mathrm{A}=$ agree; $\mathrm{N}=$ neither agree nor disagree; $\mathrm{D}=$ disagree; $\mathrm{SD}=$ strongly disagree.

\section{Social and demographic patterns in attitudinal alignment}

Previous research suggests that age, gender, educational level and location are likely to be significantly associated with non-Indigenous Australians' attitudes towards Aboriginal issues (Dunn et al. 2004; Goot and Watson 2001; Walter and Mooney 2007). To ascertain the pattern of attitudes to Aboriginal issues across these and other relevant socioeconomic and demographic variables, a principal component analysis was conducted using the six attitudinal question variables $\mathrm{Hla}, \mathrm{b}, \mathrm{c}, \mathrm{d}, \mathrm{e}, \mathrm{f}$. A single component explaining 45 per cent of the variance (Eigenvalue 2.70) was identified with reliability analyses indicating that all six variables could be used in a single scale (Cronbach's Alpha 0.75). This variable was labelled 'Attitudes towards Aboriginal issues'. Scores calculated for the 'Attitudes towards Aboriginal issues' scale were then used as the dependent variable in an ordinary least squares (OLS) regression. Independent variables were age group, gender, educational level, geographic location, ancestry, respondent income and occupation (see social proximity section for details of second OLS analysis). 
2. Keeping Our Distance: Non-Indigenous/Aboriginal relations in Australian society

Table 2.2 OLS Regression Variable Description and Coefficients Predicting 'Attitudes to Aboriginal issues' Scores

\begin{tabular}{|c|c|c|c|c|}
\hline Variable & & B & $\mathbf{N}$ & $\%$ \\
\hline Constant & & 0.255 & & \\
\hline \multicolumn{5}{|l|}{ Age } \\
\hline & $18-34$ years & 0.087 & 493 & 18.8 \\
\hline & $35-49$ years & 0.033 & 768 & 29.3 \\
\hline & $50-64$ years $\#$ & & 813 & 31.0 \\
\hline & $50-64$ years & 0.115 & 545 & 20.8 \\
\hline \multicolumn{5}{|l|}{ Gender } \\
\hline & Male ** & -0.155 & & 52.6 \\
\hline & Female & & 1248 & 47.4 \\
\hline \multicolumn{5}{|l|}{ Education $^{\# \#}$} \\
\hline & $<$ Year $12 * * *$ & -0.622 & 527 & 20.2 \\
\hline & Year $12 * * *$ & -0.481 & 281 & 10.8 \\
\hline & Trade/technical ${ }^{* *}$ & -0.673 & 437 & 16.7 \\
\hline & Certificate/diploma*** & -0.480 & 730 & 28.0 \\
\hline & Bachelor degree or above & & 634 & 24.3 \\
\hline \multicolumn{5}{|c|}{ Occupation ${ }^{\# \#}$} \\
\hline & Manager & -0.111 & 373 & 14.9 \\
\hline & Professional & & 553 & 22.1 \\
\hline & Technical/trade & -0.139 & 346 & 13.8 \\
\hline & $\begin{array}{l}\text { Community/personal Service } \\
\text { worker* }\end{array}$ & -0.212 & 240 & 9.6 \\
\hline & Clerical/administration* & -0.175 & 441 & 17.6 \\
\hline & Sales* & -0.199 & 208 & 8.3 \\
\hline & Machinery operator/driver & -0.145 & 126 & 5.0 \\
\hline & Labourer** & -0.249 & 216 & 8.6 \\
\hline \multicolumn{5}{|l|}{ Location } \\
\hline & Capital city*** & 0.242 & 1560 & 59.4 \\
\hline & Other urban* & 0.155 & 215 & 8.2 \\
\hline & Rural & & 863 & 32.5 \\
\hline \multicolumn{5}{|c|}{ Respondent individual income } \\
\hline & $\$ 0-\$ 15599$ & 0.088 & 635 & 26.0 \\
\hline & $\$ 15600-\$ 36399$ & 0.031 & 665 & 27.2 \\
\hline & $\$ 36400-\$ 77900$ & -0.083 & 804 & 32.9 \\
\hline & $\$ 78000+$ & & 342 & 14.0 \\
\hline \multicolumn{5}{|l|}{ Ancestry } \\
\hline & Euro-Australian* & 0.180 & 2466 & 93.7 \\
\hline & Non-Euro Australian & & 166 & 6.3 \\
\hline Adj $R^{2}$ & & & & 0.111 \\
\hline
\end{tabular}

$\# \mathrm{p}=0.05$

${ }^{*} \mathrm{p}<0.05$

${ }^{* *} \mathrm{p}<0.01$

${ }^{* * *} \mathrm{p}<0.000$

\#\# Collinearity diagnostics do not indicate multi-collinearity between Education and Occupation variables. 
The OLS results confirm previous research with the exception of age. Holding all other variables constant, for non-Indigenous Australians, gender, education, geographic location, occupation and ancestry are associated with 'Attitudes towards Aboriginal issues' scores. As shown in Table 2.2, Australian nonIndigenous women were significantly more likely to record higher attitude scores than Australian non-Indigenous men; those living in capital cities and other urban areas had significantly higher attitude scores than those living in rural areas; non-Indigenous people working as community and personal service workers, clerical and administration workers and sales workers and labourers are significantly more likely to record lower Aboriginal issues attitudes scores than non-Indigenous Australian professionals. Education is the most influential variable, with all non-Indigenous Australians with education levels below that of bachelor degree significantly more likely to have lower attitude scores than those with a bachelor degree or above. Interestingly, ancestry also makes a difference, with non-Indigenous Australians of Euro-Australian background having significantly higher attitude scores than Australians from other than European backgrounds. The influence of age is less marked than expected, with attitudinal scores for those aged forty-six to sixty-four (but not those aged eighteen-thirty-four years or thirty-five to forty-five years) compared with those aged sixty-five years marginally significant, falling just on the 0.05 significance level. Only non-Indigenous respondents' income was not significantly associated with attitudes towards Aboriginal issues.

\section{Social distance and social proximity}

This section addresses this chapter's second question: how socially distant from or proximate to Aboriginal people are non-Indigenous Australians? The social distance and social proximity aspects of the question are assessed separately as each reflects a different dimension of social interaction.

\section{Social distance}

The AuSSA items developed to assess the level of social distance between nonIndigenous and Aboriginal people in Australian society are based on the social distance measurement aims, but do not directly replicate the Bogardus social distance scale. The variation is because the Bogardus scale presumes that the socially distant group is migrant - that is, three of the seven Bogardus items ask about the acceptability of a group as visitors to the country or as a fellow citizen (Wark and Galliher 2007). The AuSSA questions ask respondents to nominate how happy or unhappy they would be in four hypothetical situations involving an Aboriginal person: marriage to an immediate family member; as an immediate neighbour; as a supervisor; and as a co-worker at the same level. The 
results shown in Table 2.3 indicate only limited social distance between nonIndigenous and Aboriginal Australians. Although unhappiness tends to increase as the hypothetical situation becomes socially closer - that is, the proportion of non-Indigenous Australians who would be very unhappy or unhappy about an Aboriginal person marrying into their family is higher than the proportion who would be very unhappy or unhappy working at the same level as an Aboriginal person - the general level of unhappiness is low across the four scenario items. And slightly against the general pattern of social distance scale responses, nonIndigenous respondents would be unhappier with an Aboriginal neighbour than with an Aboriginal person marrying an immediate member of their family.

\section{Table 2.3 Social Distance Scenario Attitudes}

\begin{tabular}{|c|c|c|c|c|c|c|}
\hline & How would you feel if...: & $\begin{array}{c}\text { VH } \\
\%\end{array}$ & $\begin{array}{l}\mathbf{H} \\
\%\end{array}$ & $\begin{array}{l}\mathbf{N} \\
\%\end{array}$ & $\begin{array}{l}\mathbf{U} \\
\%\end{array}$ & $\begin{array}{r}\text { VU } \\
\%\end{array}$ \\
\hline H3a. & $\begin{array}{l}\text { Aboriginal person married an immediate } \\
\text { member of your family? } \\
N=2609\end{array}$ & 11 & 25 & 53 & 8 & 3 \\
\hline H3d. & $\begin{array}{l}\text { Aboriginal person moved into the house next- } \\
\text { door to you? } \\
N=2612\end{array}$ & 14 & 26 & 46 & 9 & 4 \\
\hline H3b. & $\begin{array}{l}\text { Aboriginal person was employed in the same } \\
\text { area as you at a similar job level as you? } \\
\mathrm{N}=2632\end{array}$ & 22 & 43 & 35 & 0.4 & 0.5 \\
\hline H3c. & $\begin{array}{l}\text { Aboriginal person was made your supervisor } \\
\text { at work? } \\
N=2604\end{array}$ & 19 & 37 & 40 & 2 & 1 \\
\hline
\end{tabular}

Note: $\mathrm{VH}=$ very happy; $\mathrm{H}=$ happy; $\mathrm{N}=$ neither happy nor unhappy; $\mathrm{U}=$ unhappy; $\mathrm{VU}=$ very unhappy.

Source: Australian Survey of Social Attitudes 2007.

As in the general attitudinal data, the next question is whether social distance varies by age, gender, educational level or location. A cross-tabulation of these data with these socio-demographic variables finds statistically significant differences for each social distance scenario by gender ( $p<0.000$ for all scenarios), age ( $\mathrm{p}<0.000$ for all scenarios) and education ( $\mathrm{p}<0.000$ for all scenarios), but not by locality (not shown here). The abbreviated results summarised in Figure 2.2 present the amalgamated proportion of those who would be 'unhappy' or 'very unhappy' if the scenarios were to occur by gender, education level and age group. As can be seen, non-Indigenous women indicate an observable lower social distance than non-Indigenous men on the marriage and neighbour scenarios while those with a higher level of education, defined here as a bachelor degree or above, report lower social distance on the marriage, neighbour and work supervisor scenarios than those with a middle level of education (post-school 
qualifications below degree level). Younger non-Indigenous people are more likely to be 'very happy' and less likely to be 'unhappy' or 'very unhappy' than older people, with the level of social distance across scenarios rising with age.

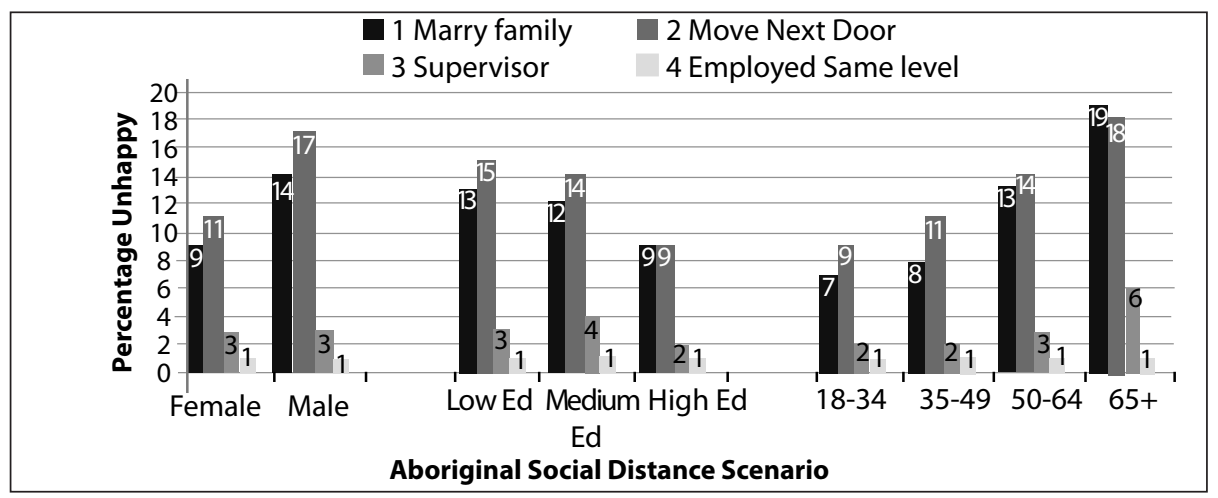

Figure 2.2 Gender, Age and Education and Social Distance Items

Note: Percentages refer to the proportion of respondents who would be 'unhappy' or 'very unhappy' with each scenario item.

Source: Australian Survey of Social Attitudes 2007.

As shown, the closer the social scenario, the higher is the proportion of all groups who would be unhappy, although again the second-closest scenario-having an Aboriginal neighbour - has higher levels of social distance than having an Aboriginal in-law for most groups. Nearly one-fifth of those aged over sixtyfive years would be unhappy or very unhappy if an Aboriginal person were to marry a member of their immediate family and a similar proportion would be unhappy should an Aboriginal person move next-door. The comparison respective 'unhappy' proportions for those aged eighteen to thirty-four years are less than half these at 7 and 9 per cent. The ratios of male to female unhappiness with these two socially closer scenarios are also higher, with the same pattern repeated between those with higher education levels and those with secondaryonly schooling.

Levels of unhappiness with the more socially remote employment scenarios were less differentiated, with the significant differences explained by the higher proportions of women, the higher educated and younger people who report they would be 'very happy' with this scenario (not shown here). Across categories and variables, the number of those who would be unhappy if an Aboriginal person were employed in the same area and level is minimal at 1 per cent or lower and the only group with more than 5 per cent of respondents unhappy with an Aboriginal supervisor is of those aged sixty-five years and over. 


\section{Social proximity}

The Bogardus distance scale presumes, in testing the relationship between ethnically different populations, a likelihood that the scenarios outlined might actually occur. This presumption is untested in Australia; the question of how much interaction there is between non-Indigenous and Aboriginal people has, to date, not been asked or answered. The very limited relevant data suggest nonIndigenous and Indigenous people occupy different spatial realms. For example, Atkinson, Taylor and Walter (2010), analysing capital-city 2006 census data, find Indigenous and non-Indigenous populations concentrated in different suburbs and areas.

To assess the dimension of social proximity, AuSSA 2007 respondents were asked to select from three descriptive statements that which most closely reflected their own level of interaction with Aboriginal people. These are

1. I mix regularly with Aboriginal people on a day-to-day basis (selected by 9 per cent)

2. I know Aboriginal people but do not mix regularly with them (selected by 45 per cent)

3. I do not know any Aboriginal people personally (selected by 46 per cent).

The second category data need to be interpreted with caution. The mailout/ mailback form of the AuSSA restricted capacity to clarify for respondents that 'knowing Aboriginal people' meant personally knowing on a one-to-one basis rather than knowing 'of' an Aboriginal person such as Cathy Freeman. Given the small number of non-Indigenous people who interact regularly it may be that a significant portion of this mid-category 'know of' rather than 'personally know' an Aboriginal person. This inadequacy will be addressed in further research on this topic. Nevertheless, these initial analyses reveal that less than one in 10 non-Indigenous Australians knows and mixes regularly with Aboriginal people and about half of all non-Indigenous Australians (at least) do not know any Aboriginal person personally.

How do these results spread across the socio-demographic variables used in the previous analyses? For this question, Category 1 data-those who report knowing personally and mixing on a day-to-day basis with Aboriginal peopleare used as the indicator of social proximity. Within the results (Figure 2.3), statistically significant differences are found within education $(\mathrm{p}<0.05)$, age ( $\mathrm{p}$ $<0.000)$ and locality $(\mathrm{p}<0.000)$. 


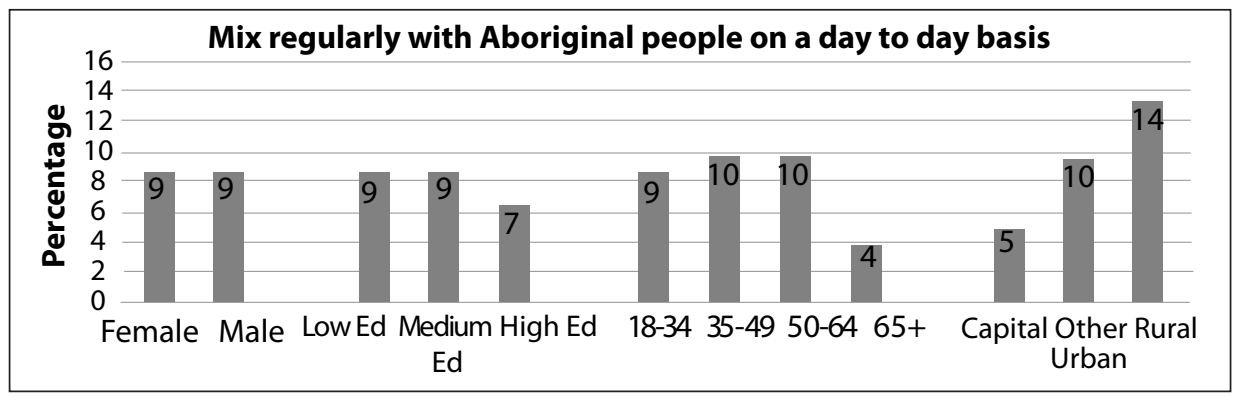

Figure 2.3 Gender, Education, Age and Locality and Aboriginal Social Proximity

Note: Percentages refer to the proportion of respondents who report they mix regularly with Aboriginal people on a day-to-day basis.

Source: Australian Survey of Social Attitudes 2007.

Non-Indigenous Australians over sixty-five years are less than half as likely to mix regularly with Aboriginal people as those in the other age groups. Nearly twothirds of this group also report they do not know any Aboriginal people compared with about 42-45 per cent of other age groups (not shown here). By locality, nonIndigenous people living in rural areas are more than twice as likely to mix regularly with Aboriginal people than those from capital cities, suggesting that interaction is more likely in smaller communities. Although not directly assessable, the higher levels of interaction among younger age groups suggest that sporting environments, rather than social networks, might be the key environments for this interaction.

Finally, to test whether social proximity to Aboriginal people had an effect on attitudes towards Aboriginal issues, the social proximity categorical variable was added to the OLS analysis described in the first section. The results show no significant difference in attitude scores between non-Indigenous Australians who 'mix regularly with Aboriginal people on a day-to-day basis' compared with those who 'know Aboriginal people but do not mix regularly with them' and those who 'do not know any Aboriginal people personally'. This finding is interpreted to indicate that interaction with Aboriginal people is not a significant factor in its own right in predicting non-Indigenous Australians' Aboriginal issues attitudes.

Table 2.4 OLS Regression Variable Description and Coefficients Predicting 'Attitudes to Aboriginal Issues' Scores

\begin{tabular}{lrrr}
\hline Variable & B & N & \% \\
\hline Constant & $\mathbf{0 . 3 4 5}$ & & \\
Social proximity & & & \\
$\quad$ Mix regularly with Aboriginal people on a day-to-day basis & & 236 & 9.1 \\
Know Aboriginal people but do not mix regularly with them & 0.012 & 1161 & 44.6 \\
$\quad$ Do not know any Aboriginal people personally & 030 & 1207 & 45.9 \\
\hline
\end{tabular}

Note: Table should be read as an addition to Table 2.3. The addition of the social proximity variable did not change the significance or the level of significance of any other variable reported in Table 2.3. 


\section{Discussion}

This chapter used AuSSA data to empirically investigate conflicting elements of the Australian national identity landscape as reflected in non-Indigenous/ Indigenous race relations. In doing so it posed two questions. The answer to the first - What are the patterns of non-Indigenous Australians' attitudes towards Aboriginal people, culture and issues and are these associated with demographic, social and/or economic characteristics? - is that: a small majority of nonIndigenous Australians tends to hold egalitarian belief systems about Aboriginal people's position in society, but, incongruously, these do not extend to the restorative actions of land rights or extra government assistance. Moreover, the overall pattern of attitudes varies across the non-Indigenous population with this variation related to socioeconomic and demographic factors. In line with previous studies, for non-Indigenous Australians, being female, residing in an urban location, being a professional and being of Euro-Australian background and especially holding a bachelor degree or higher level of education are statistically associated with more positive attitudes towards Aboriginal issues in general. In contrast with previous research, however, age does not have an independent effect. The second question asks: how socially distant or socially proximate are non-Indigenous Australians with Aboriginal people? The initial answer to this question is that while the overall social distance between nonIndigenous people and Aboriginal people is low, social distance increases with interactive closeness. On this measure, being female, younger and having a higher level of education are associated with lower levels of social distance.

The straightforward interpretation of these results is that they fit, with the notable exception of an age effect, with previous Australian attitudinal research (Dunn et al. 2004; Goot and Watson 2001; Walter and Mooney 2007) and also make theoretical sense. Older non-Indigenous Australians who show greater social distance grew up in the era before Aboriginal rights activism and this is likely to effect their reaction to the social distance items even if they have changed attitudes alongside the changing times. Similarly with gender, it might be theorised that non-Indigenous women will be more egalitarian in their attitudes given the time line similarities of calls for equality for women and Aboriginal people in Australian society. The results around education and occupation, taken here as proxies for social class position, are more definitive. Tertiaryeducated non-Indigenous professionals stand apart from non-Indigenous Australians with lower education and lower occupational status in having more positive Aboriginal issues attitudes. Moreover, education and occupation had independent effects on predicting attitude scores. The explanation may be that not only do the more educated and those in professional occupations have higher exposure to an ongoing range of opinions, perspectives and debates around Aboriginal Australia and so are more open in their attitudes, but also, more 
pragmatically, with their higher status they may be less likely to feel potential for a loss of social privilege through Aboriginal restorative action. Rural non-Indigenous Australians also tend towards conservative values (Goot and Watson 2001) and these values, it seems, are reflected in their attitudes towards Aboriginal issues. Finally, an explanation of why attitude scores are lower among non-Indigenous Australians of a non-European ancestry is immediately apparent. This group has not been included in previous analyses and the results suggest more research is needed.

The social proximity results, however, complicate this interpretation. While the attitudinal and social distance results show clear patterns, the finding that more than 90 per cent of non-Indigenous Australians do not interact regularly with Aboriginal people suggests that non-Indigenous Australians, in the main, do not occupy the same social realms as Aboriginal people. That at least half of non-Indigenous Australians do not know any Aboriginal people at all further suggests that a substantial proportion, if not a majority, of the non-Indigenous population lives their lives in a largely Aboriginal-free social zone. This finding raises the contentious issue of how and why non-Indigenous Australians hold the attitudes towards Aboriginal Australians and Aboriginal issues that they do. If non-Indigenous lives are largely separated from those of Aboriginal people, even when residing in the same geographic location, then attitudes are also predominantly formed and held without direct interaction with Aboriginal people. This interpretation is supported by the finding from the multivariate analysis that the level of social proximity did not have an independent effect on the pattern of attitudes to Aboriginal issues.

Taken together, these results suggest that most attitudes towards Aboriginal social issues are framed through interaction with other non-Indigenous people and the dominant discourse of the media and political realms. The obvious risk from being informed about Aboriginal people and issues from outside sources is that conceptions of Aboriginal people and life are more likely to be garnered through Indigenous stereotypes, which in Australia, to date, are usually pejorative. Such views are also likely to be static. The disconnect between interaction with Aboriginal people and attitudes towards Aboriginal people perhaps offers at least a partial explanation of the relative intractability of such attitudes (see Goot and Rowse 2007). It also might go some way to explaining the finding of why a belief that Aboriginal people are still disadvantaged and treated unfairly in Australian society does not seem to translate into a belief in legal, social or policy action to remedy this situation.

The upside of this analysis and interpretation, however, is that a change in the public, media and political presentation and focus on Aboriginal life from the negative (social dysfunction, alcoholism, welfare dependency) to the more positive (strong community, success against the odds, aspirations for children) 
might also result in changing attitudes. Just as the One Nation period through the mid-1990s engendered less tolerant attitudes (Walter and Mooney 2007), higher exposure to Aboriginal perspectives, perhaps, is also likely to positively influence public attitudes. Initiatives such as Reconciliation Australia's 2009 advertising campaign (ABC 2009b) to challenge negative stereotypical attitudes about Aboriginal people might just bring the ideal and reality closer together.

\section{Conclusion}

Australian social attitudes towards, and levels of interaction with, Aboriginal peoples are more than just interesting social phenomena. They form a central, if largely undiscussed, facet of contemporary Australian identity-one that this study has demonstrated remains conflicted and ill at ease. The reality of the social attitudes of a significant proportion of non-Indigenous Australians towards Aboriginal people and issues is at odds with self-conceptions of the nation as a tolerant and egalitarian society. Further, the juxtaposition of Australian egalitarian ideals with these attitudes indicates that the terrain of Indigenous/ non-Indigenous relations in Australia is still socially and politically strained. The ambiguous, and perhaps ambivalent, territory of how non-Indigenous Australians perceive the national identity place of Aboriginal Australians along with the lack of interaction between non-Indigenous and Indigenous peoples are signifiers of the ambiguous and perhaps sometimes ambivalent notions that swirl unresolved around just what it is to be Australian. A notion and a feature of Australian identity, perhaps, that will need to be resolved before the nation and its citizenry can feel at ease within its own national belonging. As a nation, we need to move past 'us' and 'them' to 'we'.

\section{References}

Atkinson, Rowland, Taylor, Elizabeth and Walter, Maggie. 2010. 'Burying Indigeneity: the spatial construction of reality and Aboriginal Australia'. Social and Legal Studies 19(3): 311-30.

Australian Broadcasting Corporation (ABC). 2009a. 'Indigenous, non-Indigenous Australians don't trust each other: study'. ABC News Online, 9 February, <http://www.abc.net.au/news/stories/2009/02/09/2486027.htm> accessed 18 March 2009.

Australian Broadcasting Corporation (ABC). 2009b. 'Campaign tackles antiIndigenous prejudice'. ABC News Online, 12 March, <http://www.abc.net. au/news/stories/2009/03/12/2514092.htm> accessed 18 March 2009. 
Australian Bureau of Statistics (ABS). 2007. Population Distribution, Aboriginal and Torres Strait Islander Australians 2006, catalogue no. 4705.0. Canberra: Australian Bureau of Statistics.

Bean, Clive, Gow, David and McAllister, Ian. 2001. Australian Election Study: User's guide for the machine-readable data file: SSDA Study No 1048. Canberra: Social Science Data Archive, The Australian National University.

Beswick, David. G. and Hills, Michael D. 1969. 'An Australian ethnocentrism scale'. Journal of Psychology 21: 211-25.

Bolt, Andrew. 2008. 'No to this racism'. Andrew Bolt Blog, The Herald Sun, 13 July, $<$ http://blogs.news.com.au/heraldsun/andrewbolt/index.php/heraldsun/ comments/no_to_this_racism/asc/P20/> accessed 10 December 2008.

Charnock, David. 1999. 'Voting at the 1998 Australian federal election: studying major and minor parties simultaneously'. In Proceedings of the 1999 Conference of the Australasian Political Studies Association, University of Sydney, Sydney, 26-29 September.

Dunn, Kevin, Forrest, James, Burnley, Ian and McDonald, Amy. 2004. 'Constructing racism in Australia'. Australian Journal of Social Issues 394: 409-30.

Fredericks, Bronwyn, Leitch, Angela and Barty, Robert. 2008. "'Big mobs in the city now": the increasing number of Aboriginal and Torres Strait Islander people living in urban areas'. Presented at World Indigenous Peoples' Conference: Education (WIPC:E), Melbourne, 7-11 December.

Goot, Murray and Rowse, Tim. 2007. Divided Nation: Indigenous affairs and the imagined public. Melbourne: Melbourne University Press.

Goot, Murray and Watson, Ian. 2001. 'One Nation's electoral support: where does it come from, what makes it different and how does it fit?'. Australian Journal of Politics and History 47(2): 159-91.

McAllister, Ian and Moore, Rhona. 1991. 'Social distance among Australian ethnic groups'. Sociology and Social Research 75(2): 95-100.

Marshall, Gordon 1998. 'Bogardus social distance scale'. A Dictionary of Sociology. $<$ http://www.encyclopedia.com/doc/1088-Bogardussocialdistancescl. html $>$ accessed 26 March 2009.

Matsuda, Yoshimi and Harsel, Sheldon. 1997. 'Factors influencing social distance from ethnic minorities, homosexuals, and the aged'. Australian Journal of Social Research 3(1): 37-56. 
Pedersen, Anne, Beven, Jiaime, Walker, Iain and Griffiths, Brian. 2004. 'Attitudes towards Indigenous Australians: the role of empathy and guilt'. Journal of Community \& Applied Social Psychology 14: 233-59.

Randall, Nancy Horak and Delbridge, Spencer. 2005. 'Perceptions of social distance in an ethnically fluid community'. Sociological Spectrum 21(2): 103-22.

Ray, John. J. 1981. 'Explaining Australian attitudes towards Aborigines'. Ethnic and Racial Studies 46(3): 348-52.

Walker, Iain. 1994. 'Attitudes to minorities: survey evidence of Western Australians' attitudes to Aborigines, Asians and women'. Australian Journal of Psychology 46(3): 137-43.

Walter, Maggie and Mooney, Gavin. 2007. 'Employment and welfare'. In Social Determinants of Indigenous Health, eds Bronwyn Carson, Terry Dunbar, Richard Chenhall and Ross Bailie, pp. 153-69. Sydney: Allen \& Unwin.

Wark, Colin and Galliher, John F. 2007. 'Emory Bogardus and the origins of the social distance scale'. The American Sociologist 38(4): 383-95.

Western, John. 1969. 'What white Australians think'. Race 10: 411-34. 